\title{
Defective Learning in Mutants of the Drosophila Gene for a Regulatory Subunit of cAMP-Dependent Protein Kinase
}

\author{
Stephen F. Goodwin, ${ }^{1}$ Maria Del Vecchio,, ${ }^{2}$ Klara Velinzon, ${ }^{2}$ Catherine Hogel, ${ }^{2}$ Steven R. H. Russell, ${ }^{3}$ \\ Tim Tully, ${ }^{2}$ and Kim Kaiser ${ }^{1}$ \\ 1/nstitute of Genetics, University of Glasgow, Glasgow G11 5JS, Scotland, ${ }^{2}$ Cold Spring Harbor Laboratory, Cold Spring \\ Harbor, New York 11724, and ${ }^{3}$ Department of Genetics, University of Cambridge, Cambridge CB2 3EH, England
}

Disruptions of a Drosophila gene encoding a regulatory subunit of cAMP-dependent protein kinase homologous to mammalian $\mathrm{RI} \beta$ (dPKA-RI) were targeted to the first (noncoding) exon of dPKA-RI via site-selected $P$ element mutagenesis. Flies homozygous for either of two mutant alleles showed specific defects in olfactory learning but not in subsequent memory decay. In contrast, olfactory acuity and shock reactivity, component behaviors required for normal odor avoidance learning, were normal in these mutants. Northern and Western blot analyses of mRNA and protein extracted from adult heads have revealed a complex lesion of the PKA-RI locus, including ex- pression of a novel product and over- or underexpression of wild-type products in mutants. Western blot analysis revealed reductions in $\mathrm{RI}$ protein in mutants. PKA activity in the absence of exogenous CAMP also was significantly higher than normal in homogenates from mutant adult heads. These two mutant alleles failed to complement each other for each of these phenotypic defects, eliminating second-site mutations as a possible explanation. These results establish a role for an RI regulatory subunit of PKA in Pavlovian olfactory conditioning.

Key words: learning; memory; reverse genetics; PKA; insertional mutagenesis; $R$ l regulatory subunit
Forward and reverse genetic strategies in Drosophila have established a role for cAMP signaling in olfactory associative learning. Disruptions of a G-protein $\alpha$ subunit $\left(G_{\mathrm{s}}\right)$, an adenylyl cyclase (rutabaga), a phosphodiesterase (dunce), a catalytic subunit of cAMP-dependent protein kinase $(D C O)$, and a cAMP-responsive transcription factor $(d C R E B 2)$ all produce deficits in learning and/or memory formation thereafter, without affecting basic sensorimotor responses to the odors or electroshock stimuli used for conditioning (for review, see Tully et al., 1996). Three of these genes (rutabaga, dunce, and $\mathrm{DCO}$ ) are expressed preferentially in mushroom bodies (for review, see Davis, 1993), characteristic anatomical structures in the insect brain (cf. Hammer and Menzel, 1995). Preferential expression of a constitutively active $G_{\mathrm{s}}$ transgene in mushroom bodies, in fact, is sufficient to abolish olfactory learning completely (Connolly et al., 1996).

Several observations in mammals suggest that modulations and subcellular distributions of cAMP-dependent protein kinase (PKA) regulatory subunits may play a pivotal role during learning and memory formation. Type I and type II PKA holoenzymes are composed of the regulatory subunit isoforms $\mathrm{RI} \alpha$ or $\mathrm{RI} \beta$ and $\mathrm{RII} \alpha$ or $\operatorname{RII} \beta$, respectively (Taylor et al., 1990). Moreover, these regulatory subunit homodimers can combine with at least three catalytic (C) subunit isoforms, $\mathrm{C} \alpha, \mathrm{C} \beta$, or $\mathrm{C} \gamma$ (Scott and Soder-

\footnotetext{
Received April 9, 1997; revised Aug. 27, 1997; accepted Aug. 29, 1997.

S.F.G was supported by a postgraduate studentship from the Department of Education for Northern Ireland. Additional support came from Medical Research Council Grants to K.K. and National Institutes of Health Grant HD32245, a McKnight Scholars Award, and a John Merck Scholarship Grant to T.T. We thank Audrey Duncanson, Jeff C. Hall, John W. Sentry, Joshua Dubnau, Gert Bolwig, John Connolly, and Marcia Belvin for helpful discussions and critical reading of this manuscript, Dan Kalderon for plasmids and the RI antibody, Kevin O'Hare for sequencing primers, Ming Yao Yang for cryostat sections, and Ed Dougherty and Brigitte Frisch for photographic assistance.

Correspondence should be addressed to Dr. Stephen F. Goodwin, Department of Biology, 235 Bassine Building, Brandeis University, 415 South Street, Waltham, MA 02254-9110.

Copyright (C) 1997 Society for Neuroscience $\quad 0270-6474 / 97 / 178817-11 \$ 05.00 / 0$
}

ling, 1992). The various PKA isoforms are expressed from different genes in a tissue-specific manner with the $\beta$-isoforms of each subunit enriched in neuronal tissue (Cadd and McKnight, 1989; McKnight, 1991). RII, but not RI, subunits are phosphorylated by activated PKA. RII also undergoes proteolytic modification (Greenberg et al., 1987; Müller and Spatz, 1989). Because both processes act to slow reassociation of the holoenzyme and thereby to prolong kinase activity, they have been suggested as molecular correlates of memory (Kandel and Schwartz, 1982; Schwartz and Greenberg, 1987; Müller and Spatz, 1989). RII, but not RI, subunits also appear to contain an anchoring domain that tethers them at specific locations within the cell, possibly adjacent to substrates for kinase activity (Bregman et al., 1989, 1991). Type I and type II PKA also may be coupled to different cell-surface receptors within the same cell (Scott, 1991). Notably, a different affinity for cAMP may result, so that neuronal responses to cAMP may vary in accordance with the specific isoform of PKA in the neuron (Cadd et al., 1990).

Type I and type II PKA activities also have been characterized in Drosophila (Foster et al., 1984). Several catalytic subunit genes and one regulatory subunit gene have been cloned by homology with mammalian counterparts (Foster et al., 1984, 1988; Kalderon and Rubin, 1988). The latter $P K A-R I$ gene most closely resembles mammalian RI $\beta$. Access to its DNA sequence allowed us to apply a relatively new technique in Drosophila to target disruptions of $P K A-R I$. We present molecular, genetic, biochemical, and behavioral data that establish a role for $P K A-R I$ in fruit fly associative learning.

\section{MATERIALS AND METHODS}

Drosophila strains and culture. Birm-2; ry ${ }^{506}$ and $w ; S b \mathrm{P}\left[r y^{+} \Delta 2-3\right] 99 \mathrm{~B} /$ TM6 (Lindsley and Zimm, 1992) were the sources of defective P elements and $\mathrm{P}$ element transposase, respectively. $R I^{715}$ and $R I^{11 D 4}$ were separately "Cantonized" by at least six rounds of backcrossing to wildtype Canton-S flies (see below). Heterozygous females, rather than 
males, were bred in each generation to allow free recombination around the $\mathrm{P}$ element insertions on the third chromosome. P element-bearing third chromosomes then were made homozygous using the double balancer strain $w$; TM3 Sb Ser e/TM6B Tb Hu e. For general purposes, flies were propagated at $18^{\circ} \mathrm{C}$ on cornmeal, molasses, and agar medium supplemented with fresh yeast. Flies to be tested for olfactory learning were raised on a $16: 8 \mathrm{hr}$ light/dark cycle at $25^{\circ} \mathrm{C}$ on a sugar-based medium (Tully and Quinn, 1985). Basic information on strains and Drosophila methods is given by Lindsley and Zimm (1992) and Ashburner (1989).

In situ hybridization to tissue sections. Single-stranded antisense and sense DNAs labeled with digoxygenin were generated by the method of Patel and Goodman (1992). The template was pcD6BO (see Fig. 2; gift from D. Kalderon, Department of Biology, Columbia University, New York, NY) linearized with either EcoRI or XbaI. In situ hybridization to tissue sections was performed as described by Han et al. (1992).

Site-selected mutagenesis. P element mutagenesis and screening was performed by a modification of the method of Kaiser and Goodwin (1990) (see also Finbow et al., 1994). Birm-2; $r y^{506}$ males were mated en masse at $16^{\circ} \mathrm{C}$ with virgin $w ; S b \mathrm{P}\left[r y^{+} \Delta 2-3\right] 99 \mathrm{~B} / T M 6$ females. $\mathrm{F}_{1} S b$ male progeny were mated, also en masse, with Canton-S virgin females at $18^{\circ} \mathrm{C}$. Groups of $10 S b^{+} \mathrm{F} 2$ virgin females were placed in single vials together with several wild-type males and were allowed to lay for several days. $F_{2}$ females from 10 vials were then pooled and used for the preparation of genomic DNA. PCR between two gene-specific primers (77F1 and 77F2; see Fig. 2) and two $\mathrm{P}$ element primers $\left(\mathrm{P}_{\mathrm{L}}\right.$ and $\left.\mathrm{P}_{\mathrm{R}}\right)$ was performed on the pooled DNA preparations (Kaiser and Goodwin, 1990). Amplified DNA was separated in $1.5 \%$ agarose gels, blotted, and probed with $\lambda \mathrm{gS} 8 \mathrm{DNA}$. The presence of a discrete band of hybridization was taken to indicate a pool of $\mathrm{F}_{2}$ females in which at least one individual contained a $\mathrm{P}$ element insertion within range of a gene-specific primer. Two such pools were identified out of 120 pools $\left(12,000 \mathrm{~F}_{2}\right.$ females $)$ tested. Progeny eclosing in the 10 vials relevant to any pool of DNA were screened by the sib-selection procedure of Kaiser and Goodwin (1990) to isolate individual flies that bred true for the insertion. Sequencing of double-stranded DNA was performed using the Sequenase version 2.0 protocol (United States Biochemicals, Cleveland, OH). Direct sequencing of PCR products recovered from agarose gels was by the modification of Winship (1989). ${ }^{32} \mathrm{P}$ probes were prepared by random priming (Feinberg and Vogelstein, 1983) of gel-purified DNA fragments, linearized plasmids, or phage DNA. Specific activities were in the range $10^{8}-10^{9}$ $\mathrm{cpm} / \mu \mathrm{g}$. For other methods, see Sambrook et al. (1989).

Gene-specific primers (co-ordinates with respect to EMBL accession number X16970; for approximate locations, see Fig. 2): 77F1, 5'GATGCAGTCCTTGAGGACTCGC, 1584-1605 (PCR primer); 77F2, 5'AGAATCCCGTGCAGTTCCTGCG, 1631-1652 (PCR primer); 77F3, 5'ACCCACCTCCGTTGATTGGCTC, 713-734 (PCR primer). P-element primers (co-ordinates with respect to EMBL accession no. V01520): $\mathrm{P}_{\mathrm{L}}$, 5'GTGTATACTTCGGTAAGCTTCGG, 36-58 (PCR primer); $\mathrm{P}_{\mathrm{R}}$, 5'AGCATACGTTAAGTGGATGTCTC, 2850-2872 (PCR primer); $\mathrm{P}_{31 \mathrm{Inv}}, 5^{\prime} \mathrm{CATGATGAAATAACATAAGGTGGTC}$ CCGTCG, 1-31 (PCR primer); $\mathrm{P}_{233-247}$, 5'ATTGTGGGAGCAGAG, 233-247 (sequencing primer); $\mathrm{P}_{2397-2412}, 5^{\prime}$ GACATTTACATACGTC, 2397-2412 (sequencing primer). $\mathrm{P}_{233-247}$ and $\mathrm{P}_{2397-2412}$ were a gift of $\mathrm{K}$. O'Hare (O'Hare et al., 1992). $\mathrm{P}_{31 \text { Inv }}$ is oriented such that amplification proceeds into the $\mathrm{P}$ element from the inverted terminal $31 \mathrm{bp}$ repeats.

Outcrossing. Because no phenotypic markers had been introduced onto the $R I^{7 I 5}$ and $R I^{11 D 4}$ third chromosomes, and because the P element itself is unmarked, the $R I$ insertions were followed through this process by PCR. Virgin females were mated each generation with Canton-S males and allowed to lay eggs for several days, after which their DNA was amplified in the presence of $77 \mathrm{~F} 1$ and $\mathrm{P}_{\mathrm{R}}$. If a female tested positive for the $\mathrm{P}$ element, virgin females were collected from among her progeny, and the above process was repeated. After six such generations, the Cantonized third chromosomes were made homozygous. Individual mating pairs of candidate heterozygous males and virgin females were allowed to generate progeny before being tested for amplification in the presence of $77 \mathrm{~F} 1$ and $\mathrm{P}_{\mathrm{R}}$. If both parents tested positive for the $\mathrm{P}$ element, mating pairs of their progeny were established and later tested for amplification in the presence of $77 \mathrm{~F} 1$ and $77 \mathrm{~F} 3$. Lines were retained only when both parents tested negative for the wild-type allele. Although somewhat laborious, this procedure allowed genuinely free recombination and the establishment of homozygosity without contribution from any other genetic background.

Associative learning. Pavlovian (classical) conditioning of odor avoid- ance responses and controls for olfactory acuity and shock reactivity were performed essentially as described by Dura et al. (1993) (for a description of the training and testing apparatus, see Tully and Quinn, 1985). Groups of $\sim 100$ individuals ( 1 - to 4 -d-old) were trained inside a tube with an electrifiable grid over $90 \%$ of its inner surface. The flies were exposed sequentially to two odors, 3-octanol (OCT; ICN-K \& K Labs) and 4-methylcyclohexanol (MCH; ICN-K \& K Labs), carried through the tube on a current of air $(750 \mathrm{ml} / \mathrm{min})$. During $60 \mathrm{sec}$ in the presence of the first odor $\left(\mathrm{CS}^{+}\right.$; OCT or $\left.\mathrm{MCH}\right)$, they received $121.25 \mathrm{sec}$ pulses of $60 \mathrm{~V} \mathrm{DC}$ at $5 \mathrm{sec}$ intervals (the unconditioned stimulus). The tube was flushed with air for $45 \mathrm{sec}$, and the flies were exposed to the second odor $\left(\mathrm{CS}^{-} ; \mathrm{MCH}\right.$ or $\left.\mathrm{OCT}\right)$ for $60 \mathrm{sec}$ without electric shock. The chamber was again flushed with air for $45 \mathrm{sec}$. For testing, the flies were transferred to the choice point of a T maze, the opposite arms of which provided converging currents of OCT and $\mathrm{MCH}(1500 \mathrm{ml} / \mathrm{min}$ at the choice point). After $120 \mathrm{sec}$, the numbers of flies in the two arms were counted. Flies remaining at the choice point were ignored $(<5 \%)$. Flies representing the 0 time point were transferred to the $\mathrm{T}$ maze within 90 sec after the end of training. Flies representing the other time points (15, 30,60 , and $180 \mathrm{~min}$ ) were removed from the training chamber and kept in standard food vials (in the dark). They were transferred to the choice point of the T maze $90 \mathrm{sec}$ before testing began. All of the above were performed at $25^{\circ} \mathrm{C}$ and $70 \%$ relative humidity in dim red light. Relative concentrations of OCT and $\mathrm{MCH}$ were adjusted such that naive flies distributed themselves 50:50 in the T maze. Each round of training and testing involved two groups of flies, differing only in the order of presentation of the two odors $\left(\mathrm{CS}^{+}, \mathrm{OCT}\right.$, and $\mathrm{CS}^{-}, \mathrm{MCH}$, for one group; vice versa for the second). For each reciprocal group, the fraction of flies making the "correct" decision (COR) was determined as the number of flies avoiding the $\mathrm{CS}^{+}$divided by the total number of flies in the T-maze arms. Finally, a performance index (PI) was calculated by averaging the $\mathrm{COR}$ values of the two reciprocal groups of flies. PIs can range from 0 (no learning) to 100 (perfect learning). Because each PI is an average of two percentages, the Central Limit Theorem predicts that they should be distributed normally (see Sokal and Rohlf, 1981). This expectation was determined to be true empirically with data from Tully and Quinn (1985) and Tully and Gold (1993) and also applies to PIs calculated from experiments on olfactory acuity or shock reactivity (see below). Consequently, untransformed (raw) data were analyzed parametrically with JMP3.1 statistical software (SAS Institute Inc., Cary, NC). All pairwise comparisons were planned. To maintain an experimentwise error rate of $\alpha=0.05$, we adjusted the critical $p$ values for these individual comparisons accordingly (Sokal and Rohlf, 1981). Three separate experiments were done for Pavlovian learning. In the first, conditioned odor avoidance responses in wild-type (Canton-S) flies and homozygous $7 I 5$ and $11 D 4$ mutants were quantified at $0,15,30,60$, and $180 \mathrm{~min}$ after one training session. In the second, conditioned odor avoidance responses in wild-type (Canton-S) and heteroallelic 7I5/11D4 mutants were quantified at $0,15,30,60,180$, and $360 \mathrm{~min}$ after one training session. In the third, conditioned odor avoidance responses in control [w(isoCJ1)] and heterozygous $715 /+$ or $11 D 4 /+$ flies were quantified immediately after one training session. All three experiments were designed in a balanced manner with two PIs per group collected per day for a total of 6 PIs per group per experiment. Mean scores for wild-type flies did not differ at any time point between the first two experiments, so the data were combined (see Fig. $3 A$ ) to yield a total of 6 PIs per group (genotype and retention time), except for Canton-S flies at $0,15,30,60$, and $180 \mathrm{~min}$ for which $n=12$ PIs. PIs from these four strains (Canton-S 7I5, 11D4, and $7 I 5 / 11 D 4)$ and five retention intervals $(0,15,30,60$, and $180 \mathrm{~min}$; the 360 min time point was not included in the analyses because it was not done for all strains) were subjected to a two-way ANOVA with genotype $(\mathrm{GENO})\left[F_{(3,130)}=86.31 ; p<0.001\right]$ and retention time $(\mathrm{TIME})\left[F_{(4,130)}\right.$ $=86.70 ; p<0.001]$ as main effects and GENO $\times \operatorname{TIME}\left[F_{(12,130)}=0.56\right.$; $p=0.87]$ as an interaction term. Values of $p$ from subsequent planned comparisons are summarized (see Fig. $3 A$ ). The fifteen planned comparisons were judged significant if $p \leq 0.003$. PIs from the three strains [w(isoCJ1), 7I5/+, and $11 D 4 /+]$ of the third experiment were subjected to a one-way ANOVA with GENO as the main effect. Subsequent unplanned comparisons of each heterozygote to control flies (with Dunnett's method) revealed significant pairwise differences $(p<0.05)$.

Olfactory acuity. Absolute odor avoidance was quantified by exposing groups of $\sim 100$ flies to converging currents of one of the odors versus air at the choice point of the T maze. Numbers of flies in each arm of the T maze were counted at the end of a 2 min exposure, and a PI was calculated as described in Boynton and Tully (1992). Each data point 
(see Fig. $3 B$ ) is a mean of 16 PIs. PIs from these three genotypes (Can-S, 715 , and 11D4) and two odors (OCT and $\mathrm{MCH})$ were subjected to a two-way ANOVA with GENO $\left[F_{(2,90)}=2.77 ; p=0.07\right]$ and odor $($ ODOR $)\left[F_{(1,90)}=1.14 ; p=0.29\right]$ as main effects and GENO $\times$ ODOR $\left[F_{(2,90)}=0.13 ; p=0.88\right]$ as the interaction term. Values of $p$ from subsequent planned comparisons are summarized (see Fig. $3 B$ ). The four planned comparisons were judged significant if $p \leq 0.01$.

Shock reactivity. Ability to sense and escape from electric shock was quantified in a T maze modified by insertion of an electrifiable grid into each arm (tubes of the same dimensions as the training tube). This procedure was performed as described in Dura et al. (1993). Each data point (see Fig. $3 C$ ) is a mean of eight PIs. PIs from these three genotypes (Can-S, 7I5, and 11D4) were subjected to a one-way ANOVA with GENO $\left[F_{(2,21)}=0.39 ; p=0.68\right]$ as the main effect. Values of $p$ from subsequent planned comparisons are summarized (see Fig. $3 C$ ). The two planned comparisons were judged significant if $p \leq 0.03$.

Northern blot analysis. Total RNA from adults was isolated using TRIzol reagent (GIBCO BRL). Adult heads were separated from bodies and appendages by sieving in liquid nitrogen (Levy and Manning, 1981). Poly $\left(\mathrm{A}^{+}\right)$RNA was purified by the PolyATtract system (Promega, Madison, WI). Five micrograms of poly $\left(\mathrm{A}^{+}\right)$RNA were separated in each lane of a $1 \%$ agarose/formaldehyde gel (Sambrook et al., 1989) and blotted onto a Hybond- $\mathrm{N}^{+}$membrane as described by the manufacturer (Amersham, Arlington Heights, IL). Hybridization was performed at $65^{\circ} \mathrm{C}$ in $5 \times$ saline-sodium phosphate-EDTA buffer (SSPE), $10 \%$ dextran sulfate, $0.04 \%$ bovine serum albumin (BSA), $0.04 \%$ polyvinylpyrrolidone, $0.04 \%$ Ficoll, $0.1 \%$ SDS, and $100 \mu \mathrm{g} / \mathrm{ml}$ sonicated salmon sperm DNA. The blots were washed in $0.2 \times \mathrm{SSC}$ and $0.1 \%$ SDS at $65^{\circ} \mathrm{C}$. Blots from two separate RNA extractions were probed with a class I-specific PCR product produced by amplification between 77FI and 77F3 (see Fig. 2 ). These blots then were reprobed with a DNA fragment from the ribosomal protein gene rp49 (O'Connell and Rosbash, 1984). PKA-RI transcript levels were normalized against $r p 49$ levels on each blot and then averaged for the two blots to yield quantitative estimates (see Results). A third blot also was probed with pBL $\pi 25.7 \mathrm{wc}$ (Voth and Lee, 1989), a P element-specific probe. Transcript sizes were deduced by comparison with an RNA size ladder (BRL).

Western blot analysis. Total protein from adult heads was extracted from $\sim 200$ flies of each genotype as described in Edery et al. (1994), with modifications to the extraction buffer (100 mM KCl, $20 \mathrm{~mm}$ HEPES, $\mathrm{pH}$ $7.5,5 \%$ glycerol, $20 \mathrm{~mm} \beta$-glycerophosphate, $100 \mu \mathrm{M}$ sodium orthovanadate, 10 mm EDTA, 0.1\% Triton X-100, 1 mm DTT, 0.5 mm PMSF, 20 $\mu \mathrm{g} / \mathrm{ml}$ aprotinin, $5 \mu \mathrm{g} / \mathrm{ml}$ leupeptin, and $5 \mu \mathrm{g} / \mathrm{ml}$ pepstatin A). Equal amounts of each extract $(\sim 100 \mu \mathrm{g})$ were separated on $7.5 \%$ SDS-PAGE gels and electroblotted to nitrocellulose membranes. After blocking with $1 \%$ BSA in Tris-buffered saline with Tween (TBST; $140 \mathrm{~mm} \mathrm{NaCl}, 10$ mM Tris-HCl, pH 7.5, and $0.05 \%$ Tween 20 ), membranes were incubated with a polyclonal rabbit anti- $P K A-R I$ antibody (kindly provided by $\mathrm{D}$. Kalderon), diluted 1:2000 in 5\% nonfat dry milk, in TBST for $2 \mathrm{hr}$. Filters were washed once for $15 \mathrm{~min}$ and 3 times for 5 min each in TBST and incubated for $30 \mathrm{~min}$ with a secondary, horseradish peroxidase (HRP)coupled anti-rabbit antibody (Amersham; 1:5000 dilution). After washing (see above), proteins were visualized using the Amersham ECL system, according to the manufacturer's instructions. After a membrane was stained with the anti-PKA-RI antibody, the same membrane was stripped (in $100 \mathrm{~mm}$ 2-mercaptoethanol, 2\% SDS, $62.5 \mathrm{~mm}$ Tris- $\mathrm{HCl}$, $\mathrm{pH}$ 6.7, for $30 \mathrm{~min}$ at $50^{\circ} \mathrm{C}$ ), blocked, and incubated with a polyclonal mouse anti$\alpha$-tubulin antibody (Sigma, St. Louis, MO; 1:200,000 dilution) as described above. The secondary antibody was HRP-coupled anti-mouse (Amersham; 1:5000 dilution).

PKA assay. Kinase assays were performed essentially as described by Lane and Kalderon (1993). Ten to 20 heads were homogenized in $200 \mu \mathrm{l}$ of buffer A (in mM: 10 sodium phosphate, pH 6.8, 1 EDTA, 0.5 EGTA, 2.5 2-mercaptoethanol, 25 benzamidine, and 1 PMSF) and centrif uged at $10,000 \times g$ for $10 \mathrm{~min}$ at $4^{\circ} \mathrm{C}$. Thirty-five microliters of extract were assayed in a total volume of $50 \mu \mathrm{l}$ containing $50 \mathrm{~mm} 3-[N-$ morpholino]propanesulfonic acid (MOPS), $\mathrm{pH} 7.0,10 \mathrm{mM} \mathrm{MgCl}_{2}, 0.25$ $\mathrm{mg} / \mathrm{ml} \mathrm{BSA}, 0.1 \mathrm{~mm} \mathrm{Kemptide}$, and $0.1 \mathrm{mM}\left[\gamma_{-}{ }^{32} \mathrm{P}\right] \mathrm{ATP}(5 \mathrm{Ci} / \mathrm{mmol})$ at $30^{\circ} \mathrm{C}$ for $45 \mathrm{sec}$, with or without $5 \mathrm{mM}$ cAMP. Incorporation of label into the Kemptide substrate was measured by spotting onto Whatman P-81 paper and washing (three times for $2 \mathrm{~min}$ each) in $75 \mathrm{~mm}$ phosphoric acid. Protein concentrations of extracts were determined using the BioRad reagent (Bradford, 1976). Two replicate assays were run per extract, and extracts from the four genotypes (Canton-S, 7I5 and 11D4 homozygotes, and 7I5/11D4 heteroallelics) were treated in parallel with the

\begin{tabular}{|c|c|c|}
\hline $\begin{array}{l}{[\mathrm{cAMP}]} \\
(\mu \mathrm{M})\end{array}$ & Strain & 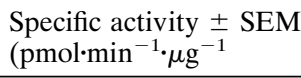 \\
\hline \multirow{4}{*}{$0^{a}$} & Can-S & $13.7 \pm 1.1$ \\
\hline & $11 D 4 / 715$ & $17.7 \pm 0.8$ \\
\hline & $11 D 4$ & $16.1 \pm 0.8$ \\
\hline & 715 & $17.0 \pm 0.9$ \\
\hline \multirow{4}{*}{$5^{b}$} & Can-S & $80.1 \pm 5.4$ \\
\hline & $11 D 4 / 715$ & $67.3 \pm 6.4$ \\
\hline & $11 D 4$ & $74.8 \pm 6.8$ \\
\hline & 715 & $75.2 \pm 4.2$ \\
\hline
\end{tabular}

${ }^{a}$ Specific PKA activity was quantified in normal and mutant flies in the absence of any exogenous cAMP $([\mathrm{cAMP}=0])$. Planned comparisons between group means after a one-way ANOVA (see Materials and Methods) revealed no significant differences between each homozygous mutant $(11 D 4$ or 715$)$ and the heteroallelic mutant $(715 / 11 D 4)(p=0.13$ and $p=0.49$, respectively) but a significant difference between the average of these three mutant groups and that of wild-type (Can-S) flies $(p<0.006) . n=4$ reactions per group, two from each of two replicate tissue homogenates.

${ }^{b}$ Specific PKA activity was quantified in normal and mutant flies at a saturating concentration of exogenous cAMP ([cAMP = 5]). Planned comparisons between group means after a one-way ANOVA (see Materials and Methods) revealed no significant differences between each homozygous mutant (11D4 or 715) and the heteroallelic mutant (715/11D4) $(p=0.43$ and $p=0.41$, respectively) or between the average of these three mutant groups and that of wild-type (Can-S) flies ( $p=$ $0.33) . n=4$ reactions per group, two from each of two replicate tissue homogenates.

experimenter (C.H.) blind to genotype. This entire experiment then was repeated to yield an $n=4$ for each group. Specific activities were calculated for each reaction tube and were determined to be normally distributed, thereby justifying parametric statistical analyses (see above). Of the 32 total values, one value for Can-S flies at [cAMP] of 0 was deemed an "outlier," because it lay more than three SDs below the mean value (and clearly indicated a failed reaction). This value was removed from the data set. Specific activity values from four genotypes (Can-S, $7 I 5,11 D 4$, and $7 I 5 / 11 D 4$ ) and two extracts (first and second) were subjected to two separate two-way ANOVAs, one for the $0 \mu \mathrm{M}$ cAMP group and one for the $5 \mu \mathrm{M}$ cAMP group with GENO $\left[F_{(3,7)}=5.88\right.$ and $p=0.025$ for $0 \mu \mathrm{M}$ cAMP; $F_{(3,8)}=0.69$ and $p=0.58$ for $\left.5 \mu \mathrm{M} \mathrm{cAMP}\right]$ and extract $(\mathrm{EX})\left[F_{(1,7)}=0.02\right.$ and $p=0.902$ for $0 \mu \mathrm{M} \mathrm{cAMP} ; F_{(1,8)}=$ 0.01 and $p=0.951$ for $5 \mu \mathrm{M} \mathrm{cAMP}]$ as the main effects and GENO $\times \mathrm{EX}$ $\left[F_{(3,7)}=3.40\right.$ and $p=0.082$ for $0 \mu \mathrm{M}$ cAMP; $F_{(3,8)}=0.63$ and $p=0.62$ for $5 \mu \mathrm{M}$ cAMP] as the interaction term. Three planned (orthogonal) comparisons for each [cAMP] group are summarized (Table 1). The planned comparisons were judged significant if $p \leq 0.05$ (corrections for experimentwise error are not necessary for orthogonal comparisons).

\section{RESULTS}

\section{The PKA-RI gene is expressed throughout the brain and at high levels in mushroom bodies}

The $P K A-R I$ gene is alternatively spliced into at least six different transcripts (classes Ia, Ib, Ic, and II-IV), all of which contain four "common" 3' exons and each of which contains a different 5' exon (see Fig. 2; Kalderon and Rubin, 1988). Class I transcripts are expressed at all developmental stages, whereas class II-IV transcripts are detected only in adults. Class I-IV transcripts are enriched in adult heads, suggesting that a predominant component of $P K A-R I$ gene expression may be within the nervous system. We examined the spatial distribution of these $P K A-R I$ transcripts in the adult brain by RNA in situ hybridization. The strongest signal from an antisense $P K A-R I$ probe was to the region of the Kenyon cell bodies (Fig. $1 A$ ). A weaker signal was apparent throughout the cell-body layer, however, and also within optic lobes (Fig. $1 B-C$ ). No signal was observed from a sense probe (Fig. $1 D$ ). Because our probe recognized all $P K A-R I$ 

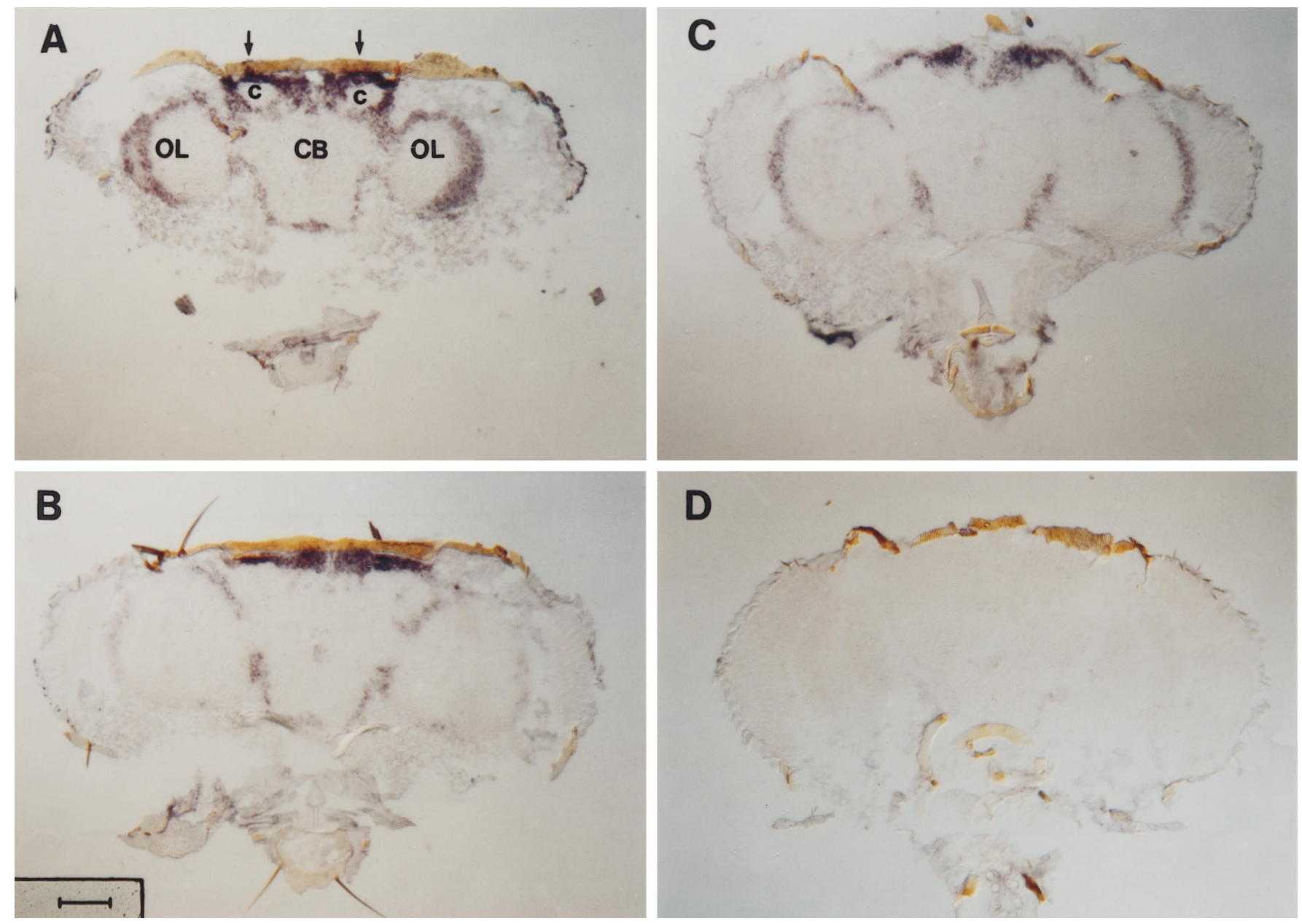

Figure 1. In situ hybridization to $P K A-R I$ transcripts in the adult brain $(200 \times$ magnification). Twelve micrometer cryostat frontal sections of wild-type (Canton-S) adult heads (male and females; no differences were observed) probed with pcD6BO (see Fig. 2). $A-C$, Antisense probe showing $P K A-R I$ expression in three serial sections of dorsal brain via mushroom bodies ( $c$, calyx of mushroom body, which is surrounded by Kenyon cell bodies; $O L$, optic lobe; $C B$, central brain). $D$, Sense probe showing no nonspecific signal.

transcripts (Fig. 2; Materials and Methods), isoform-specific patterns of expression could not be determined. Nevertheless, the preferential expression of one or more of the $P K A-R I$ transcripts in mushroom bodies (see introductory remarks) supported the hypothesis that olfactory learning might be defective in mutants of the $P K A-R I$ gene.

\section{Targeted disruption of the PKA-RI gene via site-selected $\mathbf{P}$ element mutagenesis}

The Drosophila PKA-RI locus is located at $77 \mathrm{~F}$ on the third chromosome (Kalderon and Rubin, 1988). It comprises at least five exons spanning $>16 \mathrm{~kb}$ of genomic DNA, giving rise to six (known) alternative transcripts (Fig. 2). The three class I transcripts (Ia, Ib, and Ic) differ from each other via alternative splicing (and perhaps alternative transcription starts) within the first exon. This exon encodes the N-terminal dimerization domain of RI. Class I, II, III, and IV transcripts differ from each other via alternative transcription starts and $5^{\prime}$-most exons. All six transcripts contain the four $3^{\prime}$-most common exons, which encode the cAMP- and $\mathrm{C}$ subunit-binding domains (Kalderon and $\mathrm{Ru}-$ bin, 1988). Conceptually, these alternatively spliced transcripts can yield three RI protein isoforms of 41.5 , 35, or $32.6 \mathrm{kDa}$.

A site-directed $\mathrm{P}$ element mutagenesis was performed as described in Materials and Methods to generate mutations in the
$P K A-R I$ gene. From $\sim 12,000 \mathrm{~F}_{2}$ females, two independent $\mathrm{P}$ element insertional mutations, $R I^{7 I 5}$ and $R I^{11 D 4}$, were isolated from distinct DNA pools (70 and 110) $>1$ month apart. The two resulting mutant stocks then were maintained separately (and in multiple sublines). This mutagenesis strategy results in $\sim 10$ new insertions per $\mathrm{F}_{2}$ individual and possibly in a residuum of $\mathrm{P}$ elements on the Birm-2 chromosome. Hence, to eliminate any extraneous $\mathrm{P}$ elements, we outcrossed repeatedly these two mutant lines to a wild-type (Can-S) strain, which itself is free of $\mathrm{P}$ elements. Southern blots of genomic DNA from outcrossed $R I^{715}$ or $R I^{11 D 4}$ homozygotes each yielded a single $2.6 \mathrm{~kb}$ Bam HI fragment when probed with a P element sequence (pBL $\pi 25.7 \mathrm{wc}$; Voth and Lee, 1989), confirming the presence of only one $\mathrm{P}$ element insertion in each outcrossed mutant line. This procedure also ensured that most of the "mutant" third chromosome to within \pm 5 map units of the $\mathrm{P}$ element insertion and that $>95 \%$ of the first, second, and fourth chromosomes in the outcrossed population were of wild-type Can-S origin, thereby equilibrating the genetic backgrounds of the mutant stocks with that of wildtype flies (see below; Gailey et al., 1991; Boynton and Tully, 1992; Dura et al., 1993; Tully, 1996).

The exact location of the two insertions was determined by direct sequencing of PCR products. Both $\mathrm{P}$ element insertions 


\section{A}
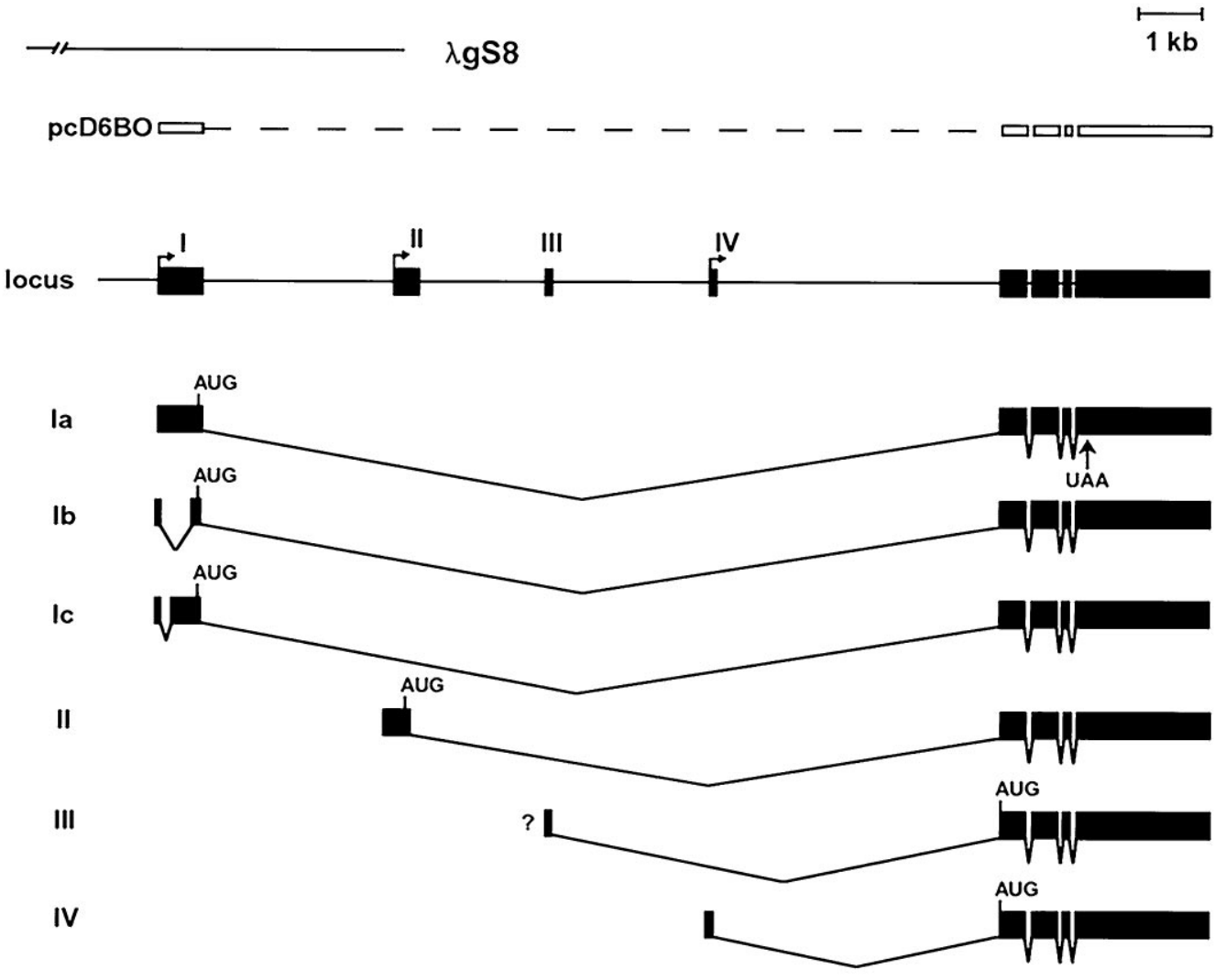

B

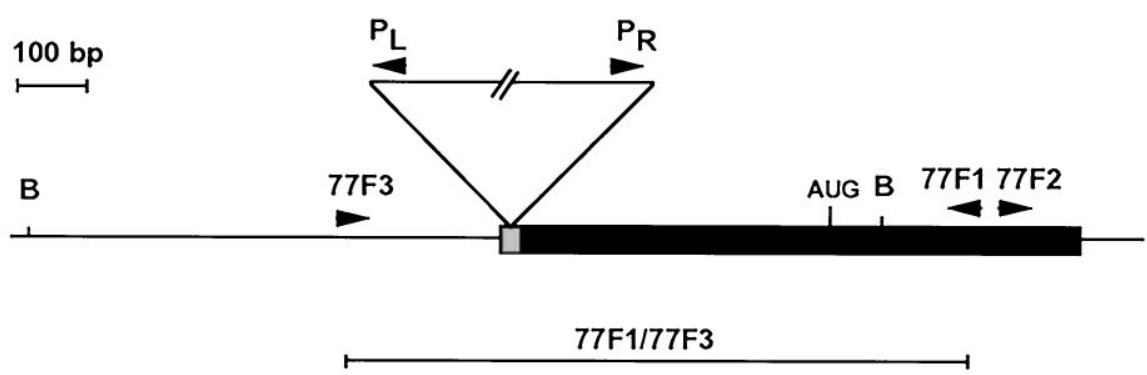

Figure 2. Structure of $P K A-R I$ gene and its relation to the $\mathrm{P}$ element insertional mutations. $A$, Structure of the $P K A-R I$ gene (after Kalderon and Rubin, 1988). $\lambda g S 8$ is a DNA clone recovered from an EMBL3 genomic library, which was used to characterize mutants of $P K A$-RI. $p c D 6 B O$ is a plasmid recovered from a cDNA library, which corresponds to a class Ia transcript and which was used as a probe to recognize all known transcripts of $P K A$ - $R I$ (see text). Locus depicts the intron and exon (black boxes) structure of the PKA-RI locus. Arrows above exons I, II, and IV indicate alternative transcription start sites for class I, II, and IV messages. The start site for the class III message has not yet been determined. $I a, I b, I c, I I, I I I$, and $I V$ represent exon maps of the six known $P K A-R I$ transcripts. $A U G$ indicates the presumed translation start sites for each. $B$, Detail of first exon of $P K A-R I$. Two identical P elements (triangle) inserted independently near the $5^{\prime}$ end of exon I (black box) in a region of heterogeneous transcription start sites (stippled box) upstream of the presumed translation start site for class I RI isoforms. 77F3, $P_{\mathrm{L}}, P_{\mathrm{R}}, 77 F 1$, and $77 F 2$ represent PCR primers used to identify and characterize the $P K A-R I$ mutants (see Materials and Methods). $77 F 1 / 77 F 3$ represents a PCR product used as a probe for class I-specific transcripts (see Fig. $4 A$ ).

were at the same position, $9 \mathrm{bp}$ from the $5^{\prime}$ end of exon 1 , within a $26 \mathrm{bp}$ region that contains heterogeneous start sites for class I transcripts (Fig. 2B; Kalderon and Rubin, 1988). Both P element insertions were in the same orientation and of the same length and seem to have been derived from a full-length P element (2.9 $\mathrm{kb}$; O'Hare and Rubin, 1983) by an internal deletion of 1848 bp between nucleotides 394-2241 (data not shown). Given that these two $\mathrm{P}$ element insertions in $R I^{7 I 5}$ and $R I^{11 D 4}$ are identical in sequence, orientation, and insertion site, they may be considered functionally equivalent with respect to any ensuing phenotypic effects.

\section{Reduced associative learning in $P K A-R I$ mutants}

Learning and memory in outcrossed, homozygous $R I^{7 I 5}$ and $R I^{11 D 4}$ mutants, in heteroallelic $R I^{7 I 5} / R I^{11 D 4}$ mutants, and in wild-type flies were assayed after one training session of the Pavlovian olfactory conditioning procedure (Tully and Quinn, 1985; Tully et al., 1994). This task quantifies conditioned odor 
A

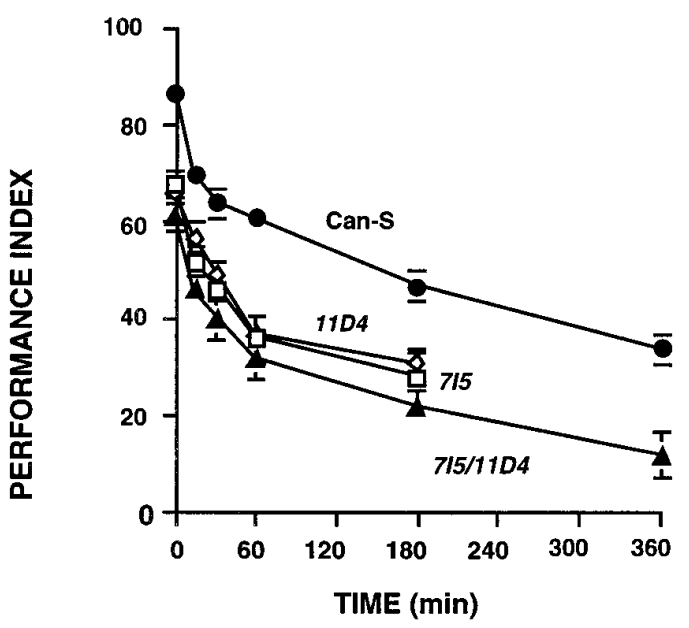

B

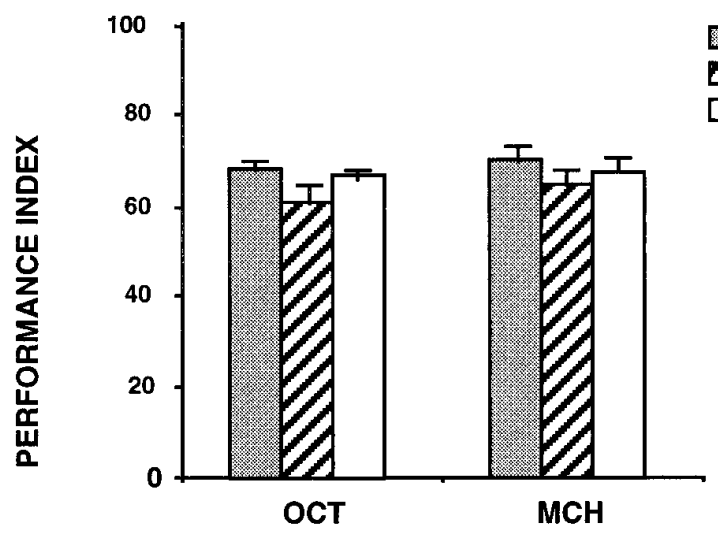

C

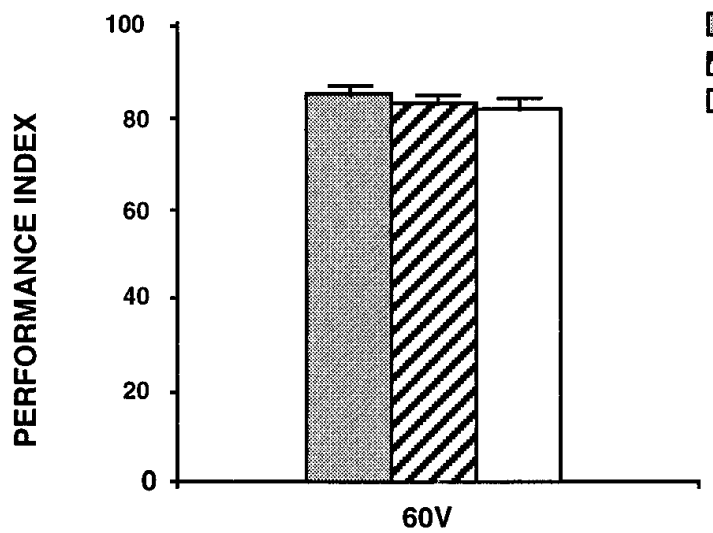

Can-s D 715 1104
Can-S

a 715 1104

Figure 3. A, Learning and memory retention of a conditioned odor avoidance response in wild-type flies, homozygous 715 or $11 D 4$ mutants, and heteroallelic 7I5/11D4 mutants. The PI is a function of the percentage of flies that avoided the shock-associated odor versus a control odor in a T maze. A PI of 0 represents a 50:50 distribution (no learning); a PI of 100 represents a 0:100 distribution (strong learning). Planned comparisons between group means at each retention time after a two-way ANOVA (see Materials and Methods) revealed significant differences between mutant $(11 D 4,715$, and $715 / 11 D 4)$ versus wild-type (Can-S) flies (all $p$ values $<0.001$ ) but no differences among the mutants (all $p$ values $>0.04$ ). For each group, $n=6$ PIs, except $n=12$ PIs for $C a n-S$ at 0,15 , 30,60 , and $180 \mathrm{~min}$ retention. Error bars indicate SEM. $B$, Olfactory acuity in untrained wild-type flies and in homozygous 715 or $11 D 4$ mutants. The ability of flies to smell the odors used during conditioning experiments was assayed by giving naive flies a choice between each odor $(O C T$ or $M C H)$ versus air in the T maze. A PI was calculated in a manner

avoidance responses that result from the temporal pairing of one odor stimulus with electroshock. A resulting PI of 0 indicates a failure to learn, and a PI of 100 indicates that $100 \%$ of the flies learned to avoid the shock-associated odor (see Materials and Methods).

Learning scores among the three mutant genotypes were similar, and each was at least $25 \%$ lower than that of wild-type flies (Fig. $3 A$ ). In contrast, the learning scores of heterozygous flies were only $8 \%$ lower than that of wild-type flies. [PIs for $11 D 4 /+$ $(79 \pm 2)$ and $7 I 5 /+(79 \pm 2)$ nevertheless were significantly lower than that for wild-type controls $(86 \pm 2) ; p=0.013$ and 0.039 for $11 D 4 /+$ and $715 /+$, respectively; $n=6$ for each group; see Discussion]. Failure of the $7 I 5$ and $11 D 4$ mutations to complement in mutant $R I^{7 I 5} / R I^{11 D^{4}}$ flies provides strong genetic evidence that the learning deficits of homozygous mutants derive from disruptions of the $P K A-R I$ gene rather than from (unknown) second-site mutations. In contrast to the effects on learning, memory decay rates in mutant flies seemed normal over the first $6 \mathrm{hr}$ after training (Fig. $3 A$; the GENO $\times$ TIME interaction term from the ANOVA was not significant; see Materials and Methods). These observations suggest that newly acquired information, although less than normal, was processed normally via short-term memory (STM), middle-term memory (MTM), and anesthesia-resistant memory (ARM) (cf. Tully et al., 1990, 1994, 1996).

The learning deficits observed in homozygous $R I^{715}$ and $R I^{11 D 4}$ mutants did not result from abnormalities in their abilities to sense, or react to, the odors, or electroshock, used during conditioning. Odor avoidance responses to OCT versus air or to $\mathrm{MCH}$ versus air (at concentrations used during conditioning; see Materials and Methods) did not differ among untrained mutant and wild-type lines (Fig. 3B). Likewise, shock avoidance responses to $60 \mathrm{~V}$ did not differ among untrained mutant and wild-type lines (Fig. 3C). These results strengthen the conclusion that the performance deficits in mutant flies observed during conditioning experiments resulted from subnormal associative learning processes.

\section{Aberrant RNA and protein processing in PKA-RI mutants}

We sought corroborative evidence of molecular abnormalities underlying this disruption of associative learning in mutants of the $P K A-R I$ gene. As discussed above, the $P K A-R I$ locus gives rise to several distinct mRNA classes transcribed from different promoters and spliced to a common body (Fig. $2 A$ ). Our siteselected mutagenesis yielded two $\mathrm{P}$ element insertions into a region of heterogeneous transcription start sites $5^{\prime}$ to the first exon (Fig. 2B; see above). Northern and Western blot analyses on

similar to that described above. Planned comparisons between group means for each odor after a two-way ANOVA (see Materials and Methods) revealed no significant differences between mutant (11D4 or 7I5) versus wild-type $($ Can-S) flies (all $p$ values $>0.15)$. For each group, $n=$ 16 PIs. Error bars indicate SEM. $C$, Shock reactivity in untrained wildtype flies and in homozygous $7 I 5$ or $11 D 4$ mutants. The ability of flies to sense the electroshock used during conditioning experiments and to escape from it was assayed by giving naive flies a choice between an electrified arm versus an unelectrified arm in the $\mathrm{T}$ maze. A PI was calculated in a manner similar to that described above. Planned comparisons between group means for each odor after a one-way ANOVA (see Materials and Methods) revealed no significant differences between mutant (11D4 or 7I5) versus wild-type (Can-S) flies (both $p$ values $>0.43$ ). For each group, $n=8$ PIs. Error bars indicate SEM. 


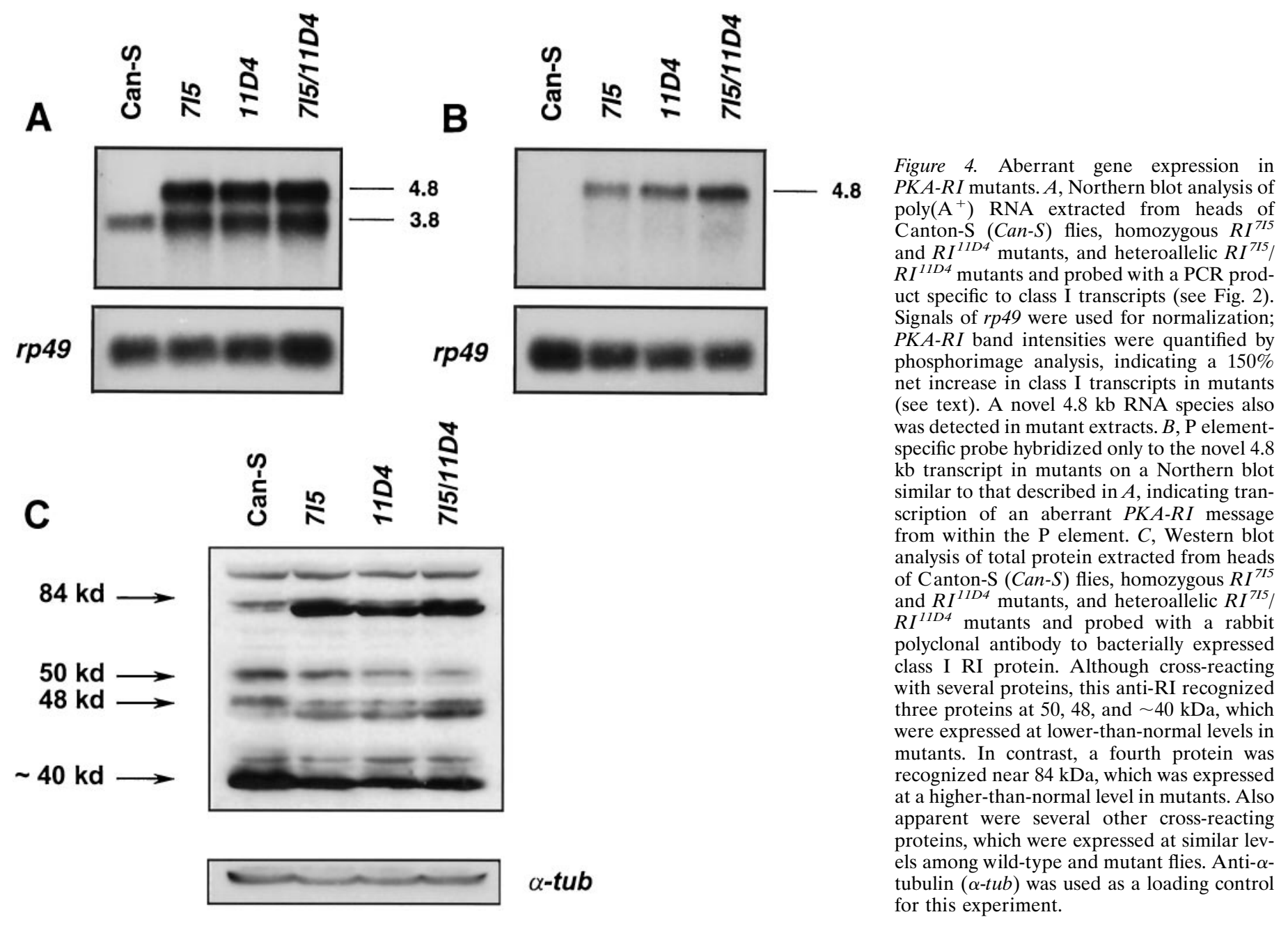

RNA or protein extracts from adult heads were done to evaluate the molecular effects of these mutations.

$\operatorname{Poly}\left(\mathrm{A}^{+}\right)$RNA was extracted from homozygous $R I^{7 I 5}$ or $R I^{11 D 4}$ mutants, heteroallelic $R I^{7 I 5} / R I^{11 D 4}$ mutants, and wildtype (Can-S) flies (Fig. 4), blotted, and probed with a PCR product (between primers $77 \mathrm{~F} 1$ and $77 \mathrm{~F} 3$ ) derived from the first exon (Fig. $4 A$ ). This probe revealed class I transcripts (Ia, Ib, and Ic were all $\sim 3.8 \mathrm{~kb}$ ) in both wild-type and mutant extracts, along with a novel $4.8 \mathrm{~kb}$ RNA species in mutant extracts (Fig. $4 A$ ). To quantify differences between the wild-type and mutant $3.8 \mathrm{~kb}$ transcripts, we prepared a second independent extract and blotted and probed it again. Concentrations of the $3.8 \mathrm{~kb}$ band then were normalized against $r p 49$ (see Fig. $4 A$ ) and averaged, indicating $152 \pm 4 \%, 153 \pm 7 \%$, and $178 \pm 2 \%$ of normal levels of the 3.8 kb transcripts in mutant $R I^{7 I 5} / R I^{7 I 5}, R I^{11 D 4} / R I^{11 D 4}$, and $R I^{7 I 5} /$ $R I^{11 D 4}$ extracts, respectively. [These quantitative increases reflect only a net effect among the three class I transcripts (Ia, Ib, and Ic). Conceivably, expression of one or more might be lower than normal and obscured by overexpression of the others. In addition, these quantitative changes might reflect differences in spatial patterns of expression.] Another Northern blot, probed with a cDNA (pcD6BO) that hybridizes with all known $P K A-R I$ transcripts, indicated that all class I-IV transcripts were present in mutant RNA extracts (data not shown).

One of these Northern blots also was reprobed with a $\mathrm{P}$ element probe. This probe hybridized with the novel $4.8 \mathrm{~kb}$ tran- script in mutant RNA extracts. Thus, this RNA species is likely derived from transcription initiation within the $\mathrm{P}$ element, which then extended into the $P K A-R I$ transcription unit.

This result also suggested that an aberrant protein may be produced from the novel RNA species in mutant flies. To pursue this notion, we extracted total protein from homozygous $R I^{7 I 5}$ or $R I^{11 D 4}$ mutants, heteroallelic $R I^{715} / R I^{11 D 4}$ mutants, and wildtype (Can-S) adult head and blotted and probed the protein with a polyclonal antibody raised against in vitro translated RI protein from a class I cDNA (kindly provided by D. Kalderon). This antibody recognized four proteins that showed differences between mutant and wild-type flies, although several cross-reacting bands, which did not differ in intensity among wild-type and mutant extracts, also were apparent (Fig. 4C). (This level of cross-reactivity also precluded an analysis of RI immunochemistry in situ; see Discussion). As a loading control, the blot was reprobed with an antibody raised against $\alpha$-tubulin (see Fig. $4 C$, bottom). Three bands, near 50,48 , and $\sim 40 \mathrm{kDa}$, were less intense in each of the mutant extracts than in that from wild-type flies. In contrast, one band near $84 \mathrm{kDa}$ was more intense in mutant extracts than in that from wild-type flies. The $50 \mathrm{kDa}$ band is of a size similar to that observed for bacterially expressed class I RI protein (D. Kalderon, personal communication). The 48 and $\sim 40$ $\mathrm{kDa}$ bands likely correspond to RI isoforms derived from class II and class III/IV transcripts, respectively, or they may be degradation products of the class I isoform. The origin of the $84 \mathrm{kDa}$ 
band is uncertain but may represent an antimorphic protein derived from the aberrant RNA transcript in mutant flies (Fig. $4 A, B)$. Its overabundance in mutant flies nevertheless suggested a potential dominant-negative role for this mutant protein (see Discussion). In any case, the $R I^{7 I 5}$ and $R I^{11 D 4}$ mutations seem to have yielded aberrant levels of expression of these proteins, and they failed to complement each other (in $R I^{715} / R I^{11 D^{4}}$ flies) for all of these molecular defects.

\section{Defective PKA biochemistry in PKA-RI mutants}

A subtle but significant defect in PKA activity also was detected in mutant genotypes. cAMP-dependent kinase activity was assayed in adult head homogenates using Kemptide as a specific substrate (Lane and Kalderon, 1993; see Materials and Methods). In the absence of any exogenous cAMP, PKA activity in heteroallelic $R I^{7 I 5} / R I^{11 D 4}$ mutants did not differ from homozygous $R I^{7 I 5}(p=0.49)$ or $R I^{11 D 4}(p=0.13)$ mutants. Mutant PKA activity was significantly higher than that of wild-type flies, however ( $p=0.006$; Table 1 . Failure to complement the mutant phenotypes of homozygous $7 I 5$ and $11 D 4$ flies by heteroallelic $R I^{7 I 5} / R I^{11 D 4}$ flies, indicates that disruption of the $P K A-R I$ gene is responsible for the biochemical abnormality (also the case for learning defects; Fig. $3 A$ ). At a saturating concentration of cAMP (5 $\mu \mathrm{M})$, PKA activity levels were similar among mutant and wild-type flies (Table 1).

These results indicate that less RI protein is available in mutants flies to bind to PKA catalytic subunits. This effect is most apparent at lower cAMP concentrations when more regulatory subunits are available to bind with PKA catalytic subunits, thereby inhibiting its activity. In contrast, fewer regulatory subunits are available to bind to catalytic subunits at higher CAMP concentrations, thereby diminishing functional differences between mutant and wild-type tissue. The difference in PKA activity between mutant and wild-type tissue at low cAMP concentration was not detected in whole-fly homogenates (data not shown), which is consistent with the observation that $P K A-R I$ is preferentially expressed in mushroom bodies of adult heads (Fig. 1). Additionally, the similarity in PKA activity between mutant and wild-type tissue at high cAMP concentration suggests the absence of any developmental or biochemical compensation in PKA catalytic activity.

\section{DISCUSSION}

Although the studies by Drain et al. (1991), Skoulakis et al. (1993), and Li et al. (1996) all provide evidence of the involvement of cAMP-dependent protein kinase in Drosophila olfactory learning, they did not reveal which endogenous regulatory subunit of PKA is involved in vivo. In particular, Drain et al. (1991) induced the expression of a murine type II transgene throughout the nervous system. Consequently, ectopic expression of the RII subunit in inappropriate cells may have disrupted learning indirectly, or alternatively, PKA activity normally modulated by RI subunits may have been disrupted artificially by overexpression of murine RII in the same neurons.

These issues raised a legitimate question about which type of endogenous regulatory subunit (RI, RII, or both) might be involved in associative learning. Because the wild-type $P K A-R I$ gene in Drosophila was cloned and because we observed one or more $P K A-R I$ transcripts to be expressed at high levels in the adult mushroom bodies (Fig. 1), we targeted disruptions of the gene via site-selected P element mutagenesis (Fig. 2; Kaiser and Goodwin, 1990). The resulting homozygous mutants (1) seem viable and fertile with no obvious morphological defects, (2) show reduced olfactory learning (Fig. $3 A$ ) without affecting sensory acuities for odor (Fig. $3 B$ ) or electroshock (Fig. 3C), (3) overexpress wild-type transcript(s) and express a novel $4.8 \mathrm{~kb}$ transcript (Fig. 4A,B), (4) underexpress three putative RI proteins and overexpress a novel protein (Fig. $4 C$ ), and (5) show increased levels of baseline PKA activity in adult head homogenates in the absence of exogenous cAMP but normal PKA activity levels in the presence of saturating concentrations of cAMP (Table 1). These phenotypic aberrations clearly are produced by disruption of the $P K A-R I$ gene, because the original $R I^{7 I 5}$ and $R I^{11 D 4}$ mutants were outcrossed to wild-type flies to remove any secondsite mutations, and subsequently, the outcrossed mutant alleles still failed to complement each other at each phenotypic level of analysis. Thus, these data argue that $P K A-R I$ is involved with olfactory associative learning.

Molecularly, an exact mechanistic explanation of how these mutations of $P K A-R I$ lead to a reduction in PKA activity and associative learning is not yet clear. The $\mathrm{P}$ element insertions into $P K A-R I$ produce a complex effect on RI expression in adult heads. First, levels of (class I) wild-type transcripts are increased. Second, a novel transcript is initiated from within the P element sequence. Third, levels of (putative) wild-type RI isoforms are decreased. And fourth, levels of an unknown protein are increased. The net effects, however, are reduced PKA activity and olfactory learning. One plausible interpretation of these molecular observations is that the mutant $4.8 \mathrm{~kb}$ transcript encodes a mutant $84 \mathrm{kDa}$ protein (Fig. $4 \mathrm{~B}$ ), which is capable of binding with wild-type RI but which then interferes with normal interactions between the +/- hybrid regulatory subunit dimers and PKA catalytic subunit dimers. Abnormal interaction with catalytic subunits then may result in a shorter half-life for wild-type RI protein(s) (Fig. 4C). One implication from this interpretation is that the $P K A-R I$ mutation might have a dominant-negative (antimorphic) effect on wild-type RI. Heterozygous $R I^{7 I 5} /+$ or $R I^{11 D^{4}} /+$ flies show only an $8 \%$ (but significant) reduction in learning compared with wild-type controls (see above), however, indicating a weak semidominant effect at best. Possibly, this dominant-negative effect might become more pronounced in homozygous mutants in which the ratio of mutant to wild-type RI protein would increase multiplicatively.

Null mutations in DCO are developmentally lethal (Lane and Kalderon, 1993). Consequently, we do not rule out the possibility that more severe mutations in $P K A-R I$ may promote maldevelopment, if not lethality. Our extant $P K A$-RI mutations, however, produce only a slight effect on PKA biochemistry: no defect is detected in whole-fly homogenates or in adult head homogenates at saturating concentrations of cAMP, and a $25 \%$ increase is detected in adult head homogenates in the absence of cAMP. This subtle biochemical defect nevertheless yields a $30 \%$ reduction in learning with no abnormalities in sensorimotor responses. The magnitude of this learning defect is similar to that produced after induced overexpression of a PKA catalytic subunit in adults (Drain et al., 1991). Taken together, these data argue that the primary effect of the $P K A-R I$ mutations is functional rather than developmental. This issue cannot be resolved fully, however, until future experiments use more sophisticated genetic tools to induce a disruption of $P K A-R I$ only in adults (cf. Drain et al., 1991; Yin et al., 1994).

Our study and others have shown in Drosophila that disruptions of both a regulatory and a catalytic subunit gene, which either decrease or increase PKA activity, all yield reductions in olfac- 
tory learning (Drain et al., 1991; Skoulakis et al., 1993; Li et al., 1996). Similarly, disruptions of rutabaga adenylyl cyclase or dunce phosphodiesterase, which either increase or decrease cAMP levels, respectively, also yield reductions in olfactory learning (for review, see Tully, 1991). Together, these results suggest an optimal range of cAMP signaling for normal adult plasticity (cf. Zhong and $\mathrm{Wu}, 1991)$. An interesting behavioral difference exists, however, between the cAMP mutants (dunce and rutabaga) and the PKA activity mutants ( $P K A-R I, D C O$, and transgenic flies overexpressing inhibitor peptide, truncated mammalian RII, or catalytic subunit). The latter seem to disrupt conditioned behavior immediately after training with no effect on memory decay rates, although the former disrupt both initial learning levels and memory decay rates. At face value, this observation suggests the direct involvement of cAMP in (short-term) memory processing. Importantly, the chronic (developmental) effects of these disruptions will have to be distinguished from their acute effects during adult learning and memory formation before more specific functions can be assigned to each component of the cAMP signaling pathway. To this end, study of a temperature-sensitive mutation of $D C O$ has revealed a temperature shift-specific effect of PKA on middle-term memory (MTM) during adult olfactory learning ( $\mathrm{Li}$ et al., 1996).

Our results neither preclude an additional role for RII regulatory subunits (see above) nor identify specific cells in the brain wherein disruption of $P K A-R I$ is required to produce the observed effect on behavioral plasticity. Future studies, using gene disruptions of Drosophila RII (which has not yet been identified genetically or cloned) or using enhancer-trap technology to restrict RI disruption or mutant RI "rescue" to specific regions of the brain (cf. Connolly et al., 1996), likely will delineate these functional subtleties. Chemical ablation of adult mushroom body neurons, however, has demonstrated a role for this brain region in olfactory associative learning (de Belle and Heisenberg, 1994; cf. Heisenberg et al., 1985). Spatially restricted disruption of Gprotein function also has indicated a role for cAMP signaling in mushroom bodies during olfactory associative learning (Connolly et al., 1996). Consistent with these interventionist experiments, the dunce, rutabaga, DCO, and $P K A-R I$ genes all seem to be expressed preferentially in mushroom bodies (Fig. 1) (Nighorn et al., 1991; Han et al., 1992; Skoulakis et al., 1993; cf. P.-L. Han et al., 1996). These observations, taken together with more general cellular considerations from work on Aplysia (Byrne and Kandel, 1996), suggest a neuronal model of olfactory associative learning in Drosophila (Fig. 5) (cf. K. A. Han et al., 1996).

In this model, mushroom body neurons (MBNs) serve to integrate sensory input from olfactory cues and footshock (electroshock). Olfactory cues lead to activity in MBNs, which produces a rise in intracellular calcium. Footshock leads to activity in modulatory neurons, which then stimulates adenylyl cyclase (AC) in MBNs via release of a monoamine neurotransmitter. A stimulatory G-protein (Gs) mediates communication between the ligand-bound neurotransmitter receptor (R?) and AC. Coincident activation of these two input paths during associative learning produces a synergistic effect on $\mathrm{AC}$ activation in $\mathrm{MBNs}$, thereby producing relatively large increases in cAMP. Excess cAMP may interact with several targets, including cyclic nucleotide ion channels (Delgado et al., 1991). Binding to RI regulatory subunit (RI) causes disassociation of RI dimers from dimers of the PKA catalytic subunit (PKA). Activated PKA then potentially phosphorylates many integral membrane proteins (?), one of which may be a potassium channel (Drain et al., 1994; Wright

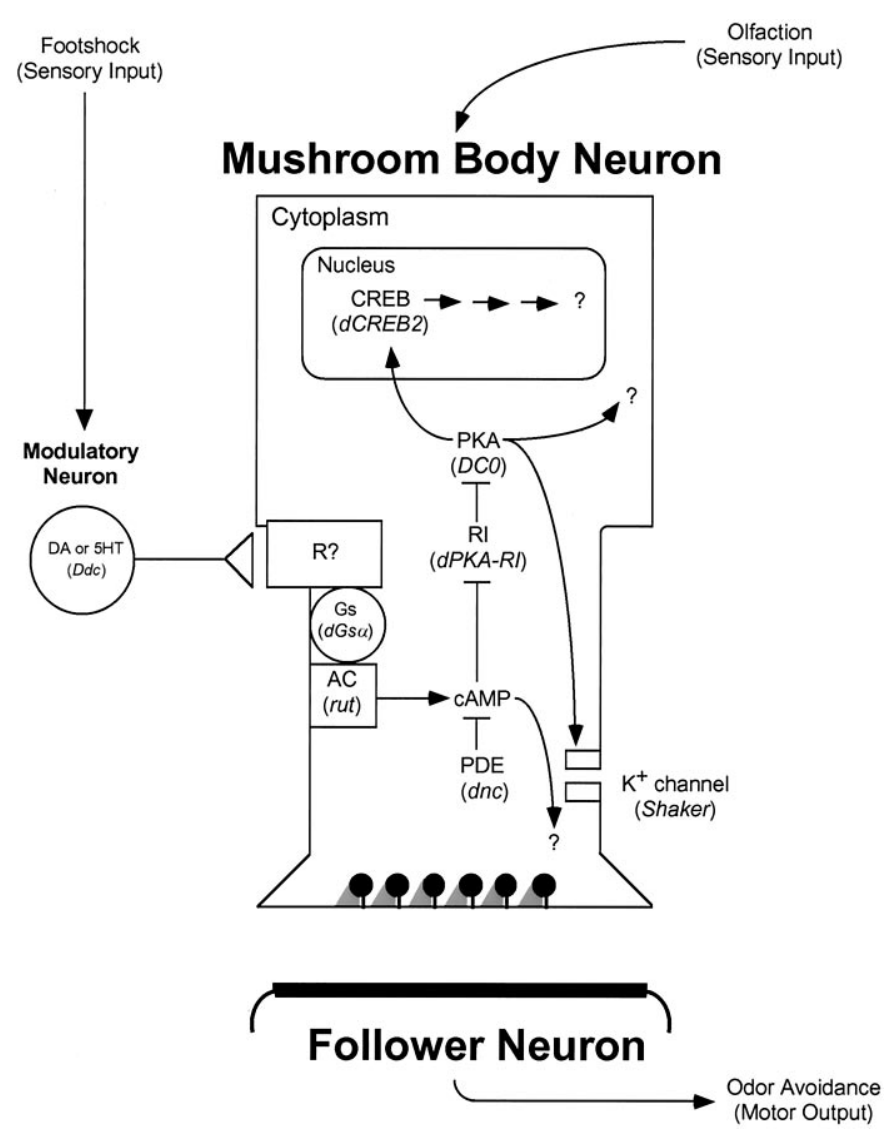

Figure 5. A neuronal model for olfactory associative learning in Drosophila, involving the cAMP signal transduction pathway. Sensory input from olfactory cues produces neural activity in mushroom body neurons $(M B N s)$, producing an increase in intracellular calcium. Sensory input from footshock also activates $M B N s$ via a modulatory neuron, which releases dopamine $(D A)$ or serotonin $(5 H T)$ synthesized by the Dopa decarboxylase $(D d c)$ gene. This monoamine neurotransmitter binds to its postsynaptic receptor ( $R$ ?) on the MBNs and activates a rutabaga (rut)encoded adenylyl cyclase $(A C)$ via a stimulatory subunit of G-protein $(G s)$, which itself is encoded by the Drosophila Gs $\alpha(d G s \alpha)$ gene. Coincident activation of $A C$ by calcium and G-protein leads to a synergistic increase in intracellular cAMP, which is hydrolyzed by dunce (dnc)encoded phosphodiesterase (PDE). Increased cAMP levels may be involved in several intracellular effects (?), but nevertheless cAMP binds to an RI regulatory subunit of PKA $(R I)$, encoded by the Drosophila $P K A-R I(d P K A-R I)$ gene. cAMP binding causes RI dimers to disassociate from dimers of the PKA catalytic subunit (PKA), encoded by $D C O$. Free $P K A$ then is able to phosphorylate many cytoplasmic targets (?), one of which is a potassium channel $\left(K^{+}\right.$channel $)$composed of Shaker subunits. Free $P K A$ also is translocated to the nuclei of $M B N s$, where it phosphorylates the CREB transcription factor (CREB) encoded by $d C R E B 2$. Phosphorylated $C R E B$ then initiates a cascade of gene expression that produces gene products (?) involved with long-term functional and structural changes at $M B N$ synapses. The neuronal effect of these biochemical changes is to increase transmitter efficacy between $M B N s$ and their follower neurons, which mediate the motor output responsible for conditioned odor avoidance responses. This model assumes MBNs to be sights of associative learning because chemical ablation of MBNs or molecular disruption of G-protein function in MBNs completely abolishes olfactory associative learning. Protein components of the signal transduction pathway are labeled only after disruptions of identified genes are shown to produce defects in olfactory associative learning that cannot be attributed to nonspecific effects on the sensory or motor responses required to perform this task. Other neural substrates or signal transduction pathways will be added to this working model as they are revealed in future studies (see text for more details). 
and Zhong, 1995). Activated PKA also is translocated into the nucleus where it may phosphorylate the CREB transcription factor (Yin et al., 1994, 1995a,b), which initiates a cascade of gene expression that ultimately produces structural and functional changes at the synapse between MBNs and follower neurons mediating conditioned odor avoidance responses (cf. Davis et al., 1996).

We have included in this model only those genes for which disruptions have yielded functional effects on olfactory associative learning (Fig. 5 legend). Thus, many mechanistic aspects of this model remain to be elucidated. To this end, a novel dopamine D1 receptor, which is expressed preferentially in MBNs, recently has been cloned in Drosophila (K.-A. Han et al., 1996). Disruptions of this candidate receptor may yet reveal whether it participates in olfactory associative learning. Similarly, no CREBdependent "downstream" genes yet are known, but they likely will reveal structural and functional components of long-term memory formation. Importantly, this model does not exclude (1) the involvement of other "associative centers" in the Drosophila brain during olfactory learning or during other types of learning (cf. Menzel et al., 1991), (2) the involvement of other signal transduction pathways (cf. Griffith et al., 1993; Kane et al., 1997), or (3) any further anatomical distinction between learning and memory storage or retrieval. Further identification of genes involved with behavioral plasticity and cellular localization of their corresponding gene products likely will discover such complexity to exist in Drosophila, as it does in other species.

\section{REFERENCES}

Ashburner M (1989) Drosophila. A laboratory manual, Ed 1. Plainview, NY: Cold Spring Harbor Laboratory.

Boynton S, Tully T (1992) Latheo, a new gene involved in associative learning and memory in Drosophila melanogaster identified from $\mathrm{P}$ element mutagenesis. Genetics 131:655-672.

Bradford MM (1976) A rapid and sensitive method for the quantification of microgram quantities of protein utilizing the principle of protein-dye binding. Anal Biochem 72:248-254.

Bregman DB, Bhattacharyya N, Rubin CS (1989) High affinity binding protein for the regulatory subunit of cAMP-dependent protein kinase II $\beta$ : cloning, characterization, and expression of cDNAs for rat brain P150. J Biol Chem 264:4648-4656.

Bregman DB, Hirsch AH, Rubin CS (1991) Molecular characterization of bovine brain P75, a high affinity binding protein for the regulatory subunit of cAMP-dependent protein kinase II beta. J Biol Chem 266:7207-7213.

Byrne JH, Kandel ER (1996) Presynaptic facilitation revisited: state and time dependence. J Neurosci 16:425-435.

Cadd G, McKnight GS (1989) Distinct patterns of cAMP-dependent protein kinase gene expression in mouse brain. Neuron 3:71-79.

Cadd G, Uhler MD, McKnight GS (1990) Holoenzymes of cAMPdependent protein kinase containing the neural form of type I regulatory subunit have an increased sensitivity to cyclic nucleotides. J Biol Chem 265:19502-19506.

Connolly JB, Roberts IJH, Armstrong D, Kaiser K, Forte M, Tully T, O'Kane CJ (1996) Associative learning disrupted by impaired Gs signaling in Drosophila mushroom bodies. Science 274:2104-2106.

Davis GW, Schuster CM, Goodman CS (1996) Genetic dissection of structural and functional components of synaptic plasticity. III. CREB is necessary for presynaptic functional plasticity. Neuron 17:669-679.

Davis RL (1993) Mushroom bodies and Drosophila learning. Neuron 11:1-14

de Belle JS, Heisenberg M (1994) Associative odor learning in Drosophila abolished by chemical ablation of mushroom bodies. Science 263:692-695.

Delgado R, Hidalgo P, Diaz F, Latorre R, Labarca P (1991) A cyclic AMP-activated $\mathrm{K}^{+}$channel in Drosophila larval muscle is persistently activated in dunce. Proc Natl Acad Sci USA 88:557-560.

Drain P, Folkers E, Quinn WG (1991) cAMP-dependent protein kinase and the disruption of learning in transgenic flies. Neuron 6:71-82.
Drain P, Dubin AE, Aldrich RW (1994) Regulation of Shaker potassium channel inactivations gating by the cAMP-dependent protein kinase. Neuron 12:1097-1109.

Dura JM, Preat T, Tully T (1993) Identification of linotte, a new gene affecting learning and memory in Drosophila melanogaster. J Neurogenet 9:1-14.

Edery I, Zwiebel LJ, Dembinska ME, Rosbash M (1994) Temporal phosphorylation of the Drosophila period protein. Proc Natl Acad Sci USA 91:2260-2264.

Feinberg AP, Vogelstein B (1983) A technique for radiolabeling DNA restriction endonuclease fragments to high specific activity. Anal Biochem 132:6-13.

Finbow ME, Goodwin SF, Meagher L, Lane NJ, Keen JN, Findlay JBC, Kaiser K (1994) Evidence that the $16 \mathrm{kDa}$ proteolipid (subunit c) of the vacuolar $\mathrm{H}^{+}$-ATPase and ductin from gap junctions are the same polypeptide in Drosophila and Manduca: molecular cloning of the Vha $16 k$ gene from Drosophila. J Cell Sci 107:1817-1824.

Foster JL, Guttman JJ, Rosen OM (1984) Drosophila cAMP-dependent protein kinase. J Biol Chem 259:13049-13055.

Foster JL, Higgins GC, Jackson FR (1988) Cloning, sequence, and expression of the Drosophila cAMP-dependent protein kinase catalytic subunit gene. J Biol Chem 263:1676-1681.

Gailey DA, Villella A, Tully T (1991) Reassessment of the effect of biological rhythm mutations on learning in Drosophila melanogaster. J Comp Physiol [A] 169:685-697.

Greenberg SM, Castellucci VF, Bayley H, Schwartz JH (1987) A molecular mechanism for long-term sensitization in Aplysia. Nature 329:62-65.

Griffith LC, Verselis LM, Aitken KM, Kyriacou CP, Danho W, Greenspan RJ (1993) Inhibition of calcium/calmodulin dependent protein kinase in Drosophila disrupts plasticity. Neuron 10:501-509.

Hammer M, Menzel R (1995) Learning and memory in the honeybee. J Neurosci 15:1617-1630.

Han K-A, Millar NS, Grotewiel MS, Davis RL (1996) DAMB, a novel dopamine receptor expressed specifically in Drosophila mushroom bodies. Neuron 16:1127-1135.

Han P-L, Levin LR, Reed RR, Davis RL (1992) Preferential expression of the Drosophila rutabaga gene in mushroom bodies, neural centres for learning in insects. Neuron 9:619-627.

Han P-L, Meller V, Davis RL (1996) The Drosophila brain revisited by enhancer detection. J Neurobiol 31:88-102.

Heisenberg M, Borst A, Wagner S, Byers D (1985) Drosophila mushroom body mutants are deficient in olfactory learning. J Neurogenet 2:1-30.

Kaiser K, Goodwin SF (1990) "Site-selected" transposon mutagenesis of Drosophila. Proc Natl Acad Sci USA 87:1686-1690.

Kalderon D, Rubin GM (1988) Isolation and characterization of Drosophila cAMP-dependent protein kinase genes. Genes Dev 2:1539-1556.

Kandel ER, Schwartz JH (1982) Molecular biology of learning: modulation of transmitter release. Science 218:433-443.

Kane NS, Robichon A, Dickinson JA, Greenspan RJ (1997) Learning without performance in PKC-deficient Drosophila. Neuron 18:307-314.

Lane ME, Kalderon D (1993) Genetic investigation of cAMPdependent protein kinase function in Drosophila development. Genes Dev 7:1229-1243.

Levy LS, Manning JE (1981) Messenger RNA sequence complexity and homology in developmental stages of Drosophila. Dev Biol 85:141-149.

Li W, Tully T, Kalderon D (1996) Effects of a conditional Drosophila PKA mutant on learning and memory. Learn Mem 2:320-333.

Lindsley DL, Zimm GG (1992) The genome of Drosophila melanogaster. San Diego: Academic.

McKnight GS (1991) Cyclic AMP second messenger systems. Curr Opin Cell Biol 3:213-217.

Menzel R, Hammer M, Braun G, Mauelshagen J, Sugawa M (1991) Neurobiology of learning and memory in honeybees. In: The behavior and physiology of bees (Goodman LJ, Fisher RC, eds), pp 323-353. London: CAB International.

Müller U, Spatz H (1989) $\mathrm{Ca}^{2+}$-dependent proteolytic modification of the cAMP-dependent protein-kinase in Drosophila wild-type and dunce memory mutants. J Neurogenet 6:95-114.

Nighorn A, Healy MJ, Davis RL (1991) The cyclic AMP phosphodiesterase encoded by the Drosophila dunce gene is concentrated in the mushroom body neuropil. Neuron 6:455-467.

O'Connell P, Rosbash M (1984) Sequence, structure, and codon prefer- 
ence of the Drosophila ribosomal protein 49 gene. Nucleic Acids Res 12:5495-5513.

O'Hare K, Rubin GM (1983) Structure of P transposable elements and their sites of insertion and excision in the Drosophila melanogaster genome. Cell 34:25-35.

O'Hare K, Driver A, McGrath S, Johnson-Schiltz DM (1992) Distribution of cloned P elements from the Drosophila melanogaster P strain $\pi_{2}$. Genet Res 60:33-41.

Patel NH, Goodman CS (1992) Detection of even-skipped transcripts in Drosophila embryos with PCR/DIG-labeled DNA probes. In: Nonradioactive in situ hybridization application manual, pp 62-63. Boehringer Mannheim Biochemica.

Sambrook J, Fritsch EF, Maniatis T (1989) Molecular cloning: a laboratory manual. Plainview, NY: Cold Spring Harbor Laboratory.

Schwartz JH, Greenberg SM (1987) Molecular mechanisms for memory: second-messenger induced modifications of protein kinases in nerve cells. Annu Rev Neurosci 10:459-476.

Scott JD (1991) The cyclic nucleotide-dependent protein kinases. Pharmacol Ther 14:1-24.

Scott JD, Soderling TR (1992) Serine/threonine protein kinases. Curr Opin Neurobiol 2:289-295.

Skoulakis EMC, Kalderon D, Davis RL (1993) Preferential expression in mushroom bodies of the catalytic subunit of protein kinase A and its role in learning and memory. Neuron 11:197-208.

Sokal RR, Rohlf FJ (1981) Biometry: the principle of statistics in biological research. New York: Freeman.

Taylor SS, Buechler JA, Yonemoto W (1990) cAMP-dependent protein kinase: framework for a regulatory diverse family of regulatory enzymes. Annu Rev Biochem 59:971-1005.

Tully T (1991) Genetic dissection of learning and memory in Drosophila melanogaster. In: Neurobiology of learning, emotion and affect (Madden IV J, ed), pp 30-66. New York: Raven.

Tully T (1996) Discovery of genes involved with learning and memory: an experimental synthesis of Hirschian and Benzerian perspectives. Proc Natl Acad Sci USA 93:13460-13467.
Tully T, Gold D (1993) Differential effects of dunce mutations on associative learning and memory in Drosophila. J Neurogenet 9:55-71.

Tully T, Quinn WG (1985) Classical conditioning and retention in normal and mutant Drosophila melanogaster. J Comp Physiol [A] 157:263-277.

Tully T, Boynton S, Brandes C, Dura J-M, Mihalek R, Préat T, Villella A (1990) Genetic dissection of memory formation in Drosophila melanogaster. Cold Spring Harb Symp Quant Biol 55:203-211.

Tully T, Préat T, Boynton SC, Del Vecchio M (1994) Genetic dissection of consolidated memory in Drosophila. Cell 79:35-47.

Tully T, Bolwig G, Christensen J, Connolly J, Del Vecchio M, DeZazzo J, Dubnau J, Pinto S, Regulski M, Svedberg B, Velinzon K (1996) A return to genetic dissection of memory in Drosophila. In: Cold Spring Harbor Symposium on quantitative biology: function and dysfunction of the nervous system. Cold Spring Harbor, NY: Cold Spring Harbor.

Voth WP, Lee CS (1989) Improved yield of helper P-element by switching its vector from pBR322 to pBluescript. Nucleic Acids Res 17:6424.

Winship PR (1989) An improved method for directly sequencing PCR amplified material using dimethyl sulphoxide. Nucleic Acids Res 17:1266.

Wright NJD, Zhong Y (1995) Characterization of $\mathrm{K}^{+}$currents and the cAMP-dependent modulation in cultured Drosophila mushroom body neurons identified by lacZ expression. J Neurosci 15:1025-1034.

Yin JCP, Wallach JS, Del Vecchio M, Wilder EL, Zhou H, Quinn WG, Tully T (1994) Induction of a dominant-negative CREB transgene blocks long-term memory in Drosophila. Cell 79:49-58.

Yin JCP, Vecchio MD, Zhou H, Tully T (1995a) CREB as a memory modulator: induced expression of a $d C R E B 2$ isoform enhances longterm memory in Drosophila. Cell 81:107-115.

Yin JCP, Wallach JS, Wilder EL, Klingensmith J, Dang D, Perrimon N, Zhou H, Tully T, Quinn WG (1995b) Drosophila CREB/CREM homolog encodes multiple isoforms including a PKA-responsive transcriptional activator and antagonist. Mol Cell Biol 15:5123-5130.

Zhong Y, Wu CF (1991) Altered synaptic plasticity in Drosophila memory mutants with a defective cAMP cascade. Science 251:198-201. 